International Journal of Agricultural Policy and Research Vol.9 (7), pp. 173-181, December 2021

Available online at https://www.journalissues.org/IJAPR/

https://doi.org/10.15739/IJAPR.21.020

Copyright (C) 2021 Author(s) retain the copyright of this article

ISSN 2350-1561

CrossMark

\&click for updates

Original Research Article

\title{
Levels of adoption of new rice farm management technologies among smallholder farmers in Kilombero District, Tanzania
}

\author{
Lawi Samwel Mhoja ${ }^{1 *}$, \\ Harrieth G. Mtae ${ }^{1}$ \\ and \\ Cosmas Haule ${ }^{1}$

\footnotetext{
${ }^{1}$ Department of Development Studies of the Open University of Tanzania.

*Corresponding Author Email: lawi.mhoja@yahoo.com
}

This study examined levels of adoption of new rice farm management technologies among smallholder farmers in Kilombero district, Tanzania. Adoption of improved rice seeds, Site-Specific nutrient technology; directseeded-rice technology, as well as pests and diseases technology variables were examined. A total of 99 smallholder rice farmers adopting new rice technologies from four villages (Mofu, Namwawala, Idete, and Machipi) were sampled through simple random sampling for quantitative data. Data were collected using questionnaire which aimed to capture levels of adoption of new rice farm management technologies among smallholder farmers. 20 farmers from 99 farmers who happened to be given certificates of appreciation by the government as successful adopters were used to collect qualitative data. Descriptive statistical analysis was used to analyse quantitative data. Thematic analysis was used to analyse qualitative data. Findings of this study revealed that, there are variations of adoption of new rice farm management technologies among smallholder farmers in Kilombero district (active, moderate, and low). This implies that, there are technologies adopted by farmers and also there are technologies which are ignored by farmers. It is recommended that, smallholder farmers should engage in active adoption to improve farming practices and increase rice production. The government of Tanzania should conduct national agricultural exhibitions in villages to help farmers access easily the agricultural information. Also the government of Tanzania should evaluate the competence of the agricultural extension officers located in rural areas.

Keywords: Adoption levels, new rice farm management technologies, smallholder farmers.

\section{INTRODUCTION}

Agriculture is the dominant sector in Tanzanian economy, providing livelihood, income and employment to over 80 percent of the population accounting for 60 percent of export earnings and 56 percent of the country's Gross Domestic Production (GDP) (NBS, 2015). It is an important economic sector in terms of food production, employment generation, production of raw materials for industries and generation of foreign exchange. Over 80 percent of the arable land is used by the smallholders (NBS, 2017). Food crops accounts for about 65 percent of agricultural GDP with maize crop accounting for over 20 percent (NAP, 2013). About 50 percent of the cultivated land in Tanzania is allocated to cereal crops which serve as major staple crops (FAOSTAT, 2014).

Rice is the second most important staple crop followed by wheat and sorghum. Of the total area under rice cultivation, 
rain-fed lowland rice accounts for 74 percent whereas irrigated rice accounts for 26 percent respectively with Kilombero district being one of the highest rice producing districts in Tanzania (Pallangyo et al., 2019).

New rice technologies are the technologies that improve rice production (Rehman et al., 2016). New rice farm management technologies include all kinds of improved techniques and practices which affect the growth of rice output (Rehman et al., 2016). The majority of smallholder farmers in developing countries rely on traditional methods of production and this has lowered the level of productivity. For instance, over $70 \%$ of maize production in most developing countries is from smallholders who use traditional methods of production (Rehman et al., 2016).

Loevinsohn et al. (2013) define adoption as the integration of new technology into existing practice and is usually proceeded by a period of 'trying' and some degree of adaptation. For Rogers (2003), adoption is a decision of "full use of an innovation as the best course of action available" and rejection is a decision "not to adopt an innovation".

Adoption of improved agricultural technologies has been associated with higher earnings and lower poverty; improved nutritional status; lower staple food prices; increased employment opportunities as well as earnings for landless laborer (Kariyasa, 2011). However, the rate of adoption of these technologies has remained low in most developing countries including Tanzania. About $80 \%$ of production in Tanzania comes from subsistence farmers who rely on traditional farming methods especially hand hoe and rainfall agriculture resulting to poverty incidence among smallholder farmers (Levitan, 2017).

Adoption of new rice technologies depends on farmers' knowledge of their existence; that is farmers adopt a technology if they have a complete understanding of new rice technology (Mubofu, 2017). From economic perspective, farmers decide to choose a new technology based on the benefits of technology although rice farming systems' agronomic benefits may be easy to recognize the economic benefits (Kadigi et al., 2020). The unrealized potential of new farming technologies may offset the adoption rate of the respective technologies, especially when the farmer has limited full information about the technology and its potential (Mubofu, 2017).

Several efforts have been done by the government of Tanzania like allocating agricultural extension officers in every ward; providing motor cycles the agricultural extension officers to facilitate transfer of agricultural knowledge to farmers to increase the rate of adoption of new rice farm management technologies but still adoption of new rice farm management is low (Misaki et al., 2016). Several studies have been conducted on adoption levels among smallholder farmers like Mubofu (2017); Mkenda et al. (2017); Massawe et al. (2020) but still adoption of new rice farm management is still low. However, several studies examined levels of adoption by comparing adopters and non-adopters but there are limited studies on adoption levels among a single group (adopters). Therefore, this study was interested to examine adoption levels of new rice farm management technologies focusing on adopters only to see if they adopt all technologies or some technologies are ignored to create variations of adoption within the same group of adopters in Kilombero district Tanzania.

\section{Literature Review}

\section{Adoption Levels of Improved Rice Seeds Among Smallholder Farmers}

Yamano et al. (2016) found that the New Rice for Africa (NERICA) adoption rate in Cotd'voire was 4 percent in the study area, but the authors speculated that the adoption rate could have been 28 percent in 2000 if the whole population were exposed to and had access to its seed in 2000 or before.

Kijima et al. (2011) in Uganda found that more than 50 percent of farmers who cultivated NERICA varieties in 2004 discontinued using them by 2006. This was disappointing because an earlier study by the same authors found NERICA varieties to be promising in reducing poverty. Kijima et al. (2011) found that the profitability of NERICA- depended largely on rainfall in Uganda, where rice was cultivated in upland. Where and when rainfall failed, NERICA profitability was low relative to alternative crops, and farmers discontinued using NERICA. This suggests that the use of NERICA will be limited to areas where farmers have access to surface water, such as rivers or ponds.

Kangile et al. (2018) conducted a study in three regions in Tanzania (Mbeya, Morogoro, and Shinyanga. A survey was conducted in which a multistage sampling method comprising four stages was used. In the first stage, three regions (Mbeya, Morogoro, and Shinyanga) were identified based on the level of rice production and diversity in agroecologies.

The second stage was a purposive selection of one district in each region using these criteria (a) high level of rice production (b) number of rice farmers (c) investment in rice production. Accordingly, the Kahama district from Shinyanga, Kilombero from Morogoro, and Kyela from Mbeya were selected. The third stage involved the selection of six wards in each district using, random sampling method. The fourth and last stage involved a random selection of 20 rice farmers in each of the selected wards (Kangile et al., 2018).

Thus, the total sample size was 360 (120 farmers from each district). Data were analyzed using STATA 12 Software package; the analysis involved both descriptive statistics and regression analysis. Results revealed that about 26 percent of the farmers in the three districts had grown one or more improved rice varieties in the recent past using seeds from either formal or informal sources (Kangile et al., 2018).

Mligo and Msuya (2015) in Kilombero district found that out of 120 respondents 45.0 percent planted local rice seed varieties, 43.3 percent planted recommended rice varieties that is TXD 306 rice seed variety. Other 11.7 percent did not 
plant the recommended rice seed variety which is TXD 306.

\section{Adoption levels of Site-Specific-Nutrient Technology Among Smallholder Farmers}

A study by Sheahan and Barrett (2017) showed that from the six Living Standards Measurement Study-Integrated Surveys on Agriculture (LSMS-ISA) in the Sub-Saharan countries, fertilizer and agrochemical use is more widespread than is often acknowledged. One-third of the cultivating households in the Living Standards Measurement Study-Integrated Surveys on Agriculture (LSMS-ISA) countries apply inorganic fertilizer and the average unconditional nutrient application rate is $25 \mathrm{~kg} / \mathrm{ha}$ (corresponding to $57 \mathrm{~kg}$ of total fertilizer $/ \mathrm{ha}$ ).

A study by the Agricultural Sector Development Programme (ASDP) which was conducted in Tanzania in 2009 and 2010 on the use of chemicals reported that fertilizer use increased marginally from 12 percent to 13 percent, whilst the use of insecticides and fungicides declined from 17 percent to 14 percent. These results differ due to fertilizer use across all crops being minimal, varying from $5 \mathrm{~kg} / \mathrm{ha}$ to $8 \mathrm{~kg} / \mathrm{ha}$, though annual nutrient depletion is estimated at $61 \mathrm{~kg} / \mathrm{ha}$. Tanzania has some of the worst soil nutrient depletion in the region leading to extensive fertilizer use all the more compelling (FAO, 2015). Wilson (2016) in the Kilombero district found that adoption of sitespecific-nutrient technology was low.

\section{Adoption Levels of Direct-Seeded-Rice Technology Among Smallholder Farmers}

Rohila et al. (2015) conducted a study in Haryana state in India on levels of adoption of Direct Seeded Rice (DSR) technology. Four districts Yamuna Nagar, Kurukshetra, Karnal, and Kaithal were selected purposively because of the maximum cultivation of rice under these four districts. From each district, one block with a maximum area under Direct Seeded Rice (DSR) culture was selected purposively Viz, Sadhaura from Yamuna Nagar, Shahbad from Kurukshetra, Assand from Karnal, and Pundri from Kaithal.

Further two villages, namely, Sarawan and peerbholi from block Sadhaura; Malikpur and Basantpura villages from block Shahbad; Rugsana and Chochra villages from block Assandh and Fanal and Hubri villages from block Pundri were selected purposively because maximum DSR culture was under these villages. From each village, 15 farmers were selected randomly, who were growing rice in DSR culture, making a total of 120 farmers respondents. The data were collected with the help of well-structed interview schedule. The data were analyzed and tabulated after applying suitable statistical techniques like frequency, percentage, means, and rank orders (Rohila et al., 2015).

Results pertaining to the overall adoption of DSR show that majority of farmers ( 35.83 percent) belonged to the low level of adoption category followed by 34.17 percent medium adoption level and only 30 per cent to high level of adoption. In Nutshell, 70 percent of farmers had a low to medium levels of adoption meaning that farmers had not adopted the full package of practices recommended by the agricultural experts. It may be due to poor knowledge of DSR coupled with long attachments with conventional method of cultivation (Rohila et al., 2015).

Loevinsohn et al. (2012) who conducted a study in SubSaharan African countries found that farmers' decisions about whether and how to adopt direct-seeded-rice technology are conditioned by the dynamic interaction between characteristics of the technology itself and the array of conditions and circumstances. He then concluded that due to complications of direct-seeded-rice technology only a small number of farmers adopt this technology.

Mukasa (2016) conducted a study in Tanzania and Uganda on the use of Direct Seeded Rice (DSR) technology. Mukasa (2016) found that farmers adopting DSR technology were on average of 57.41 per cent and 25.51 percent respectively. Furthermore, they relied more on family labor and hired more labor force than non adopting farmers. Their land productivity (value of harvest per unit of cultivated land) was also on average significantly large providing some insights on the potential positive correlation between adoption of Direct Seeded Rice (DSR) technology and farm productivity (Mukasa, 2016). Wilson (2016) in Kilombero district found that adoption of directseeded-rice technology was low.

\section{Adoption Levels of Pests and Diseases Technology Among Smallholder Farmers}

In India adoption of pest management technology is high due to the advancement of Information Communication Technology (ICT) applications (Pushpa et al., 2018). With the advancement of ICT applications, more webs-based intelligent information systems are developed and this allows users real-time online information related to pests in particular and agriculture as a whole (Pushpa et al., 2018).

The Agricultural Sector Development Programme (ASDP) performance report for 2009/2010 in Tanzania indicated that the use of insecticides and fungicides declined from 17 percent to 14 percent $(F A O, 2015)$. In Tanzania and Uganda Mukasa (2016) found that only 1.14 percent and 2.09 per cent respectively adopted pesticides. Wilson (2016) in Kilombero district found that adoption of pests and diseases technology was low. Previous studies examined levels of adoption by examining adopters and non-adopters of new rice farm management technologies. However, little is known on levels of adoption of new rice farm management among a single group (adopters) in Tanzania. Hence, this study endeavored to study levels of adoption among smallholder farmers by focusing on adopters only to discover if there are variations of adoption within a single group.

\section{MATERIAL AND METHODS}

The study was conducted in Kilombero District in Morogoro 


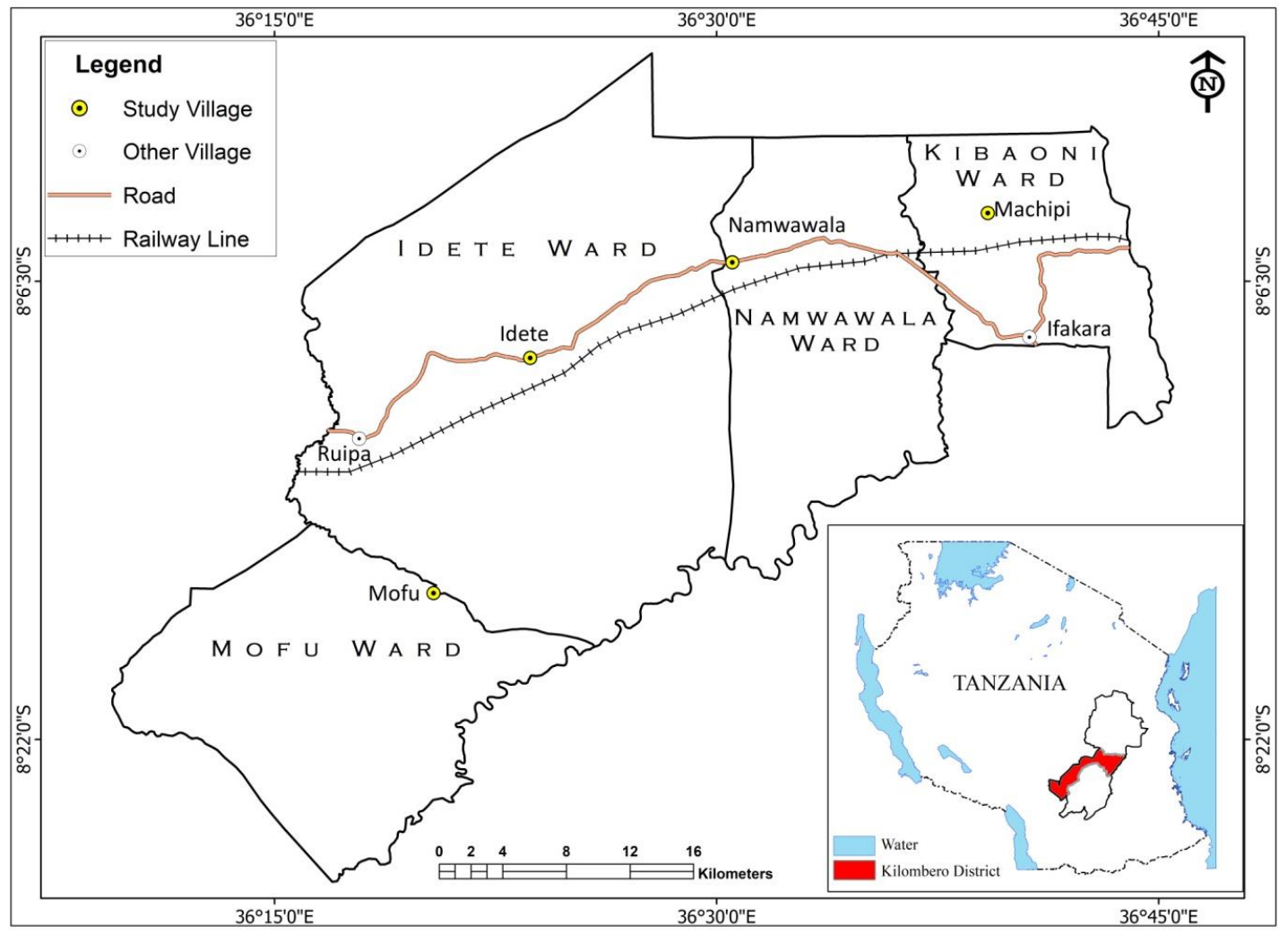

Figure 1: Map of Kilombero District (2021)

region, Tanzania from four villages (Mofu, Namwawala, Idete, and Kibaoni (Machipi Village). Kilombero district was chosen because it is among the areas where the cultivation of rice is in large amounts compared to other districts in the Morogoro region (Mombo, 2017). The study population for this study consisted of smallholder rice farmers from the selected villages. The majority of the households living in Kilombero District are generally poor farmers and fishermen highly depending on crop cultivation, livestock rearing, fishing, and hunting (Mombo, 2017). Since most people especially small-scale farmers depend on agriculture to support their living, agriculture is the main activity practiced in Kilombero district (Mombo, 2017). In Kilombero District both rain-fed and irrigated agriculture is practiced (Mombo, 2017).

According to the 2012 national census, the Kilombero district is home to more than 407,880 people (Gebrekidan et al., 2020). The population growth rate is about 3.9 percent as revealed from the year $2012(407,880$ people) to 2016 (475,329 people), and is projected to reach 1,021,657 people by the year 2036 (Wilson et al., 2017). The majority of the population lives in rural areas with low population density. Mang'ula and Ifakara are the two most populated divisions in Kilombero, with a population density of 22 persons $/ \mathrm{km}^{2}$. The high population density is attributed to being a district capital and large-scale sugar cane plantation, respectively (Gebrekidan et al., 2020) Figure 1.
Immigration into the district has increased dramatically due to the perceived availability of high-quality and cheap farmland (Gebrekidan et al., 2020). Conflicts between pastoralists and farmers over land use are a chronic and widespread problem that has resulted in injury and litigation disputes (Gebrekidan et al., 2020). The Kilombero has a diverse ethnic profile. Ndamba, Mbunga, and Pogoro are considered native to Kilombero district and arrived in the early $19^{\text {th }}$ century from Malawi. Other groups who migrated to Kilombero district include the Sagara (Central Tanzania), Hehe (Iringa), Ndedeule (Zambia), Sukuma (Mwanza), Ngoni (Southern Tanzania), Ngindo (Rufiji), and Chaga (Kilimanjaro) (Gebrekidan et al., 2020).

Within the Kilombero district, socioeconomic drivers generate a multitude of productive activities, primarily for farming. Important activities include agriculture and forestry, urbanization and transport, flood protection, hydropower, navigation, and recreation, which all but in different ways add pressure to the flood plain ecosystem (Gebrekidan et al., 2020).

In recent years, a rapid increase in agricultural land use has been observed. Most of the district's land in Kilombero was used for the temporary annual crop planted in monoculture, with paddy and maize being the dominant ones (Gebrekidan et al., 2020). Kilombero district contributed close to 70 percent of the regional planted area under paddy rice. Livestock production has notably 
increased in the district since 2006. The natives generally do not keep livestock, and most of the livestock are owned by either pastoralists or agropastoralists who migrated into the district (Gebrekidan et al., 2020).

In the Kilombero district, there is an increased in access to agricultural mechanization services, including tractors, power tillers, weeders, and harvesters (Gebrekidan et al., 2020). Farmers in the Kilombero district use significantly more family and wage labor for land preparation, weeding, and harvesting of rice. The adoption of more diverse cropping systems depends fundamentally on the hydrological regime of a particular farm (Gebrekidan et al., 2020). In the Kilombero district, the majority of farmers still use traditional farming practices. Poor infrastructure and insecurity increase the costs and risks of commercialization for agropastoralists located in remote areas (Gebrekidan et al., 2020).

\section{Sample Size}

A sample size of 99 respondents (households) was used. Because Kilombero district comprises larger farmers, medium farmers, smallholder farmers, and other people who engage in other economic activities and no government statistics showing the population for smallholder rice farmers only, this means that the population for drawing sample size was not known. Therefore, Cochran's sample size formula was used to determine the sample size for this study.

$n=\frac{Z_{\frac{\alpha}{2}}{ }^{2} p q}{e^{2}}$

Where:

$n$ is a sample size

$\mathrm{Z}$ is values of 1.96 (95\% Confidence level, $\alpha=5 \%$ significance level).

$P$ is the (estimated) proportion of the population that has the attribute in question which is (0.5).

$q$ is $1-p=0.5$

$e$ is the desired level of precision (i.e. the margin of error) $=$ 0.0985

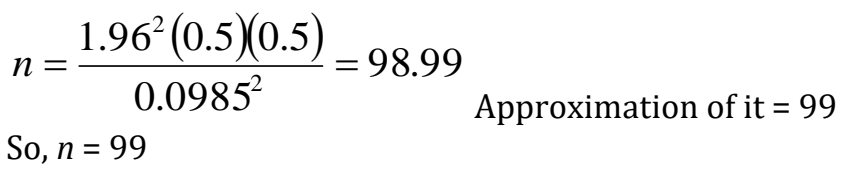

\section{Sampling Procedures}

This section presents sampling procedures.

\section{Sampling Frame}

The lists of household heads (leaders of the households) from the households which depend and engage mostly in rice production and who also adopt new rice technologies were used as sampling frame (respondents) in this study.

\section{Simple Random Sampling}

This method was used in selecting randomly the 99 smallholder rice farmers who adopt new rice technologies with the assistance of the street leaders. Village Executive Officers (VEO) also assisted the researchers in selecting farmers whose main source of income was rice farming.

\section{Purposive Sampling}

Under this sampling, 20 smallholder farmers who happened to be given by the government certificates of appreciation as successful adopters from 99 smallholder farmers were sampled for qualitative data.

\section{Data Collection}

Quantitative data were collected from respondents through the use of a questionnaire, and was administered to 99 respondents using face-to-face interviews. Closed ended questions were included in the questionnaire. 20 successful adopters from 99 farmers (adopters) were used to collect qualitative data.

\section{Data Analysis}

Regarding quantitative data analysis, descriptive analysis was applied in the interpretation of ordinal scale through the application of 3-points likert scale (score of 1, 2, 3) after being coded and entered into SPSS Version 20. Percentage tables were used to gain understanding of the respondents. This assisted the researcher to gain useful types of information on levels of adoption of new rice farm management technologies among smallholder farmers. This assisted in drawing conclusions and making recommendations in this study. Qualitative data was analysed using thematic analysis. Thematic analysis was used to identify, organize, and offer insight into patterns of meaning (themes) across a dataset. The collected qualitative data were grouped into similar ideas and coded accordingly to simplify data analysis. Patterns matching technique was used where the information collected were arranged in groups with similar meanings (themes). However, in drawing conclusions, emerging patterns were matched and analysed. This assisted in clarifying information acquired through quantitative approach and in making recommendations in this study.

\section{RESULTS AND DISCUSSION}

\section{Adoption Levels of New Rice Farm Management Technologies}

This section presents results on adoption levels of improved rice seeds technology, site-specific nutrient 
Table 1. Descriptive statistics for adoption of improved rice seeds technology

\begin{tabular}{lcc}
\hline Level of Adoption & Frequency & Percent \\
\hline Low & 25 & 25.3 \\
Moderate & 14 & 14.1 \\
High (active) & 60 & 60.6 \\
Total & 99 & 100.0 \\
\hline
\end{tabular}

Source: Field Data, 2019

Table 2. Descriptive statistics for adoption of site-specific nutrient technology

\begin{tabular}{lcc}
\hline Level of Adoption & Frequency & Percent \\
\hline Low & 36 & 36.4 \\
Moderate & 6 & 6.1 \\
High (active) & 57 & 57.6 \\
Total & 99 & 100.0 \\
\hline
\end{tabular}

Source: Field Data, 2019

technology, direct-seeded-rice technology as well as pests and diseases technology among smallholder farmers in Kilombero District Morogoro, Tanzania.

\section{Adoption Levels of Improved Rice Seeds among Smallholder Farmers}

To assess adoption levels of new rice farm management technologies among smallholder farmers in Kilombero district, the study examined the adoption of improved rice seeds technology of respondents. The results are presented in Table 1.

Table 1 revealed that $60.6 \%$ of adopters were high (active), $25.3 \%$ were low while $14.1 \%$ were moderate in the Kilombero district. These results show that the majority of adopters (66.6\%) were active adopters of improved rice seeds. This is further supplemented by a key informant (male of 43 years) from Idete village, who said that,

"I use improved rice seeds but I am discouraged to continue using improved rice seeds because the training we receive from agricultural extension workers on the utilization of improved rice seeds is inadequate".

Other informants (65s years) from Namwawala village insisted that,

"The government of Tanzania should have a proper way of evaluating the competence of the agricultural extension officers who are placed in rural areas."

This finding differs from the findings by Asfaw et al. (2012) in a study conducted in Ethiopia who found out that adoption of improved seed varieties is low. The difference is context-based because this research focused on one crop in particular (rice) and that of Asfaw et al. (2012) focused on different varieties of crops.

\section{Adoption Levels of Site-Specific-Nutrient Technology}

The study assessed the adoption of site-specific-nutrient technology of respondents to ascertain adoption levels of new rice farm management technologies among smallholder farmers in Kilombero district. The results are presented in Table 2.

The findings in Table 2 shows that $57.6 \%$ of adopters were high (active), 36.4\% were low and 6.1\% were moderate adopters. These results suggest that there is a variation of adoption of site-specific-nutrient technology in Kilombero district whereby the majority of adopters were active in the technology. Further finding from a key informant (female, 39 years) from Machipi village who reported that,

"I don't use site-specific-nutrient technology because when I used it previously, I discovered that the technology is very costly as it needs inviting an expert to perform soil nutrient testing or soil nutrient mapping for him/her to advise on the kind of fertilizer to be used to realize high yields".

I advise to the government of Tanzania that, it should establish agriculture centres in villages where smallholder farmers can easily access agricultural information because this will stimulate smallholder farmers to adopt site-specific nutrient technology".

The results of this study differs with the study by Barua (2015) who found that, Tanzania has been suffering from lower and stagnant productivity growth due to the lower use of improved fertilizers. For instance, only $7.2 \%$ of all farmers use inorganic fertilizer. The quantity of fertilizer usage is relatively low (i.e. $7 \mathrm{~kg} / \mathrm{ha}$ ) in Tanzania (Barua, 2015). The difference is contextual based due to the fact that this study used only adopters but that of Barua used adopters and non-adopters.

\section{Adoption Levels of Direct-Seeded-Rice Technologies}

Under the Direct-Seeded-Rice technology, sowing of rice seeds is done directly in the soil where they are to grow, rather than transplanting seedlings (Pathak et al., 2011). In 
Table 3. Descriptive statistics for adoption of direct seeded rice technology

\begin{tabular}{lcc}
\hline Level of Adoption & Frequency & Percent \\
\hline Low & 37 & 37.4 \\
Moderate & 11 & 11.1 \\
High (active) & 51 & 51.5 \\
\hline Total & $\mathbf{9 9}$ & $\mathbf{1 0 0 . 0}$ \\
\hline
\end{tabular}

Source: Field Data, 2019

Table 4. Descriptive statistics for adoption of pests and diseases technology-H3

\begin{tabular}{lcc}
\hline & Frequency & Percent \\
\hline Low & 30 & 30.3 \\
Moderate & 10 & 10.1 \\
High (active) & 59 & 59.6 \\
\hline Total & $\mathbf{9 9}$ & $\mathbf{1 0 0 . 0}$ \\
\hline
\end{tabular}

Source: Field Data, 2019

examining adoption levels of new rice farm management technologies among smallholder farmers in Kilombero district, the study assessed adoption of direct-seeded rice technology of respondents. The results are presented in Table 3 . Table 3 shows that $51.5 \%$ were high (active), $37.4 \%$ were low, while $11.1 \%$ were moderate. These results show that not all adopters were utilizing direct-seeded-rice technology in Kilombero district though the majority of adopters were active. The findings are supplemented by a key informant (male, 58 years) from Mofu village, who said that,

"I avoid using direct-seeded rice technology due to lack of capital because when I used the technology, I discovered that the technology demands enough capital".

Another informant (female, 60 years) from Idete village insisted that,

"The government of Tanzania should provide loans to smallholder farmers to motivate them to utilize the directseeded rice technology"

Findings of this study differ with that of Barua (2015) who found that in Tanzania only $2.4 \%$ of agricultural households have access to credit to manage use direct seeded rice technology because this technology is costly. The difference is contextual based because this study examined only adopters while that of Barua compared adopters and nonadopters.

\section{Adoption Levels of Pests and Diseases Technologies}

The study investigated adoption levels of pests and diseases management technology of respondents in order to examine adoption levels of new rice farm management technologies among smallholder farmers in Tanzania. The results are presented in Table 4.

Table 4 shows that $59.6 \%$ were high (active), $30.3 \%$ were low while $10.1 \%$ were moderate. The results show that the majority of adopters used pests and diseases technology actively in Kilombero district. Furthermore, this result is supplemented by a key informant (female, 40 years) from Namwawala village, who said that,

"I don't adopt pests and diseases technologies (like white grubs, rice yellow mottle virus, and armyworm which are found in our area) instead I adopt other technologies due to its complications in use and most of them are detailed in English language".

Another informant (male, 38 years) from Machipi insisted that,

"The government of Tanzania should create a chain to coordinate agricultural researchers, and agricultural extension officers to tackle the complications of pests and diseases technology.

This study is similar with that of the United Republic of Tanzania Prime Minister's Office (2014) which reported that agricultural pest management in Tanzania is still underdeveloped due to inadequate resources for research.

\section{Conclusions}

This study established that, there are technologies which are adopted and there are technologies which are not adopted by adopters of new rice farm management technologies in Kilombero district. This implies that, there is variation of adoption (active, moderate, and low) of new rice farm management technologies among smallholder farmers in Kilombero district.

\section{Recommendations}

i) There is a need for smallholder farmers to engage in active adoption of new rice farm management 
technologies.

ii) The government of Tanzania should conduct national agricultural exhibitions in villages to stimulate adoption of new rice farm management technologies.

iii) The government of Tanzania should establish agriculture centres in villages to help smallholder farmers to access easily agricultural information to improve farming practices and increase rice production.

iv) The government of Tanzania should have a proper way to evaluate competence of agricultural extension officers in rural areas.

\section{Further Study}

i) Further study should be conducted on levels of adoption of post-production technologies among smallholder farmers.

\section{Disclosure of Conflict of Interest}

The authors have not declared any conflict of interest.

\section{Acknowledgement}

We would like to thank the Morogoro Regional Commissioner for his permission to undertake the study in Morogoro region. Also, this gratitude goes to the Kilombero District Commissioner, Village Executive officers (VEO) of Mofu, Namwawala, Idete, and Machipi for their perrmission, clearance and support to carry out the study in their areas of jurisdiction.

\section{REFERENCES}

ASDP (2011). Agricultural Sector Development Programme Performance Report, 2010/2011. Final draft. The United Republic of Tanzania.

Asfaw S, Shiferaw B, Simtowe F, Lipper L (2012). Impact of modern agricultural technologies on smallholder welfare: Evidence from Tanzania and Ethiopia. Food Policy, $37(3): 285-296$.

Barua P (2015). Factors affecting technology adoption among smallholder maize farmers in Tanzania. https://www.researchgate.net/publication/299730609-

Factors-Affecting-Technology-Adoption-among-

smallholder-maize-farmers-in-Tanzania.pdf.

FAO (2015). The economic lives of smallholder farmers. FAO, Rome. https://www.fao.org.

FAOSTAT (2014). Africa Maize Production-2012/2013. https://faostat3.fao.org/browse/Q/QC/E

Gebrekidan BH, Heckelei T, Rasch S (2020). Characterizing Farmers and Farming System in Kilombero Valley Floding Plain, Tanzania. https://www.mdpi.com/pdf.PDF

Kadigi IL, Mutabazi KD, Philip D, Richardson JW, Bizimana JC, Mbungu W, Mahoo HF, Sieber S (2020). An Economic Comparison between Alternate Rice Farming Systems in Tanzania Using a Monte Carlo Simulation Approach.
https://www.mdpi.com/pdf.PDF

Kagile JR, Gebeyehu S, Mollel H (2018). Improved Rice Seed use and Drivers of Source Choice for Rice Farmers in Tanzania, J. Crop Improvement, 32(3):1-13.

Kariyasa K, Dewi A (2011). Analysis of factors affecting Adoption of integrated crop management Farmer Field Schools (ICM-Ffs) in Swampy Areas. Int. J. Food Agric. Econ. 1(2):29-38.

Kijima Y, Otsuka K, Sserunkuruma D (2011). An Inquiry into Constraints on a Green Revolution in Sub-saharan Africa: the case of NERICA rice in Uganda, World Dev. 39(1):7786.

Levitan J (2017). Investing in Rural People. http://www.ifad.org/documents/10180/feb514f1-a0d24111-8d98-50be8ddd0184

Loevinsohn M, Sumberg J, Diagne A (2012). Under what circumstances and conditions does adoption of technology result in increased agricultural productivity? Protocol. London: EPPI Centre, Social Science Research Unit, Institute of Education, University of London.

Massawe BHJ, Kaaya AK, Slater BK (2020). Involving Smallholder Farmers in the Agricultural Land Use Planning Process Using Analytic Hierarchy Process in Rice Farming Systems of Kilombero Valley, Tanzania. Afr. J. Agric. Res., 14(7):395-405.

Misaki E, Apiola M, Gaiani S (2016). Technology for Small Scale farmers in Tanzania: A Design Science Research Approach. The Electronic Journal of Information System in Developing Countries, 74(1):1-15,

Mkenda P, Ndakidemi P, Mbega E (2017). Accessibility of Agricultural Knowledge and Information.

Mligo F, Msuya CP (2015). Farmers Adoption of Recommended Rice Variables: A case of Kilombero District of Morogoro Region, Tanzania. S. Afr. Jn l. Agric. Ext. 43(1),

Mombo F (2017). Conservation and Livelihoods: Where do we strike a balance to sustain the Wetlands in Kilombero valley? Research Journali's Journal of Agriculture, 4(7), 5

Mubofu C (2017). Disseminating Agricultural Research Information: A case study of Frmers in Mlolo, Lupalama and Wenda Villages in Iringa district, Tanzania, University of Dar-es-salaam Library Journal, 12(2). https://www.ajol.info/index. PhP/article/download

Mukasa AN (2016). Technology Adoption and Risk Exposure among Smallholder Farmers: Panel Data Evidence from Tanzania and Uganda. Working Paper Series. African Development Bank, https://www.afdb.org/Documents/PublicationsPDF

NAP (National Agricultural Policy (2013). Economic Survey 2012 Ministry of Agriculture Livestock and Fisheries Dares-salaam, Tanzania, P. 2.

NBS (2017) National Population Projection Tanzania National Bureau of Statistics

NBS (National Bureau of Statistics (2015). Annual Agricultural Sample Survey Report 2014/2015. National Bureau of Statistics, Dar-es-salaam, Tanzania

Pallangyo B, Mdily K, Mkondo C, Kibola A (2019). Crop 
Pests Control Measures and Potential Impact in Kihansi Catchment Area, Tanzania J. Sci. 45(4):650-660.

Pathak S, Tewari A, Dubey DS, Sankhy S (2011). DirectSeeded Rice: Potential, Performance and Problems - A Review. https://www.researchgate.net/publication/267944086Direct-seeded-rice-potential-performance-

Pushpa S, Sing KM, Brajesh S (2018). Information and Communication Technologies for Integrated Pest Management - Some Experiences, htpps://mpra.ub.unimuenchen.de/MPRA-PAPER-PDF

Rehman A, Jingdong L, Khatoon R, Iqbal MS Hussain I (2016). Effect of Agricultural Growth on Poverty Reduction, its Importance and Suggestions. Transylvanian Review, 25(5)

Rogers, E.M. (2003). Diffusion of Innovations ( $5^{\text {th }}$ ed.), The Free Press, New York

Rohila AK, Ghanghas BS Shehrawat PS (2015). Adoption Status of Direct Seeded Rice Cultivation Technology in Haryana, Annals of Agri Bio Research, 20(1):115-117.

Sheahan M, Barrett CB (2017). Ten Striking Facts about Agriculture Input Use in Sub-saharan Africa, Food Policy, 12-25.

United Republic of Tanzania Prime Minister's Office (2014). Integrated Pest Management Plan, https://www.kilimo.go.tz/uploads/statistics/R....PDF

Wilson ED, McInnes R, Mbaga DP, Paul O (2017). Kilombero Valley, United Republic of Tanzania. Ramsar Advisory Mission Report, Ramsar Site No. 1173, https://www.ramsar.org/documents/library/ra--PDF

Wilson RT (2016). The Rice Value Chain in Tanzania, Internal Journal of Agriculture Innovations and Research, $7(2): 2319-2473$.

Yamano T, Labarta R, Arauna A, Huelgas Z (2016). Adoption and impacts of international rice research technologies. https://www.researchgate.net/publication/293821102Adoption-and-impacts-of-international-. 